\title{
Analysis of the strain behaviour of a friction stir processed superplastic aluminium alloy
}

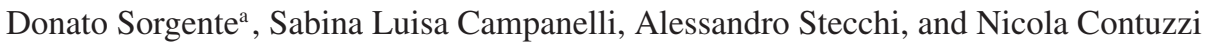 \\ Department of Mechanics, Mathematics and Management, Politecnico di Bari, Viale Japigia, \\ 182, 70126 Bari, Italy
}

\begin{abstract}
Superplastic forming is a well-established process by which very large, very complex shaped and also multi-sheets components can be manufactured in a single step. Combining this process with a suitable joining technique is of great industrial interest. In this work the strain behaviour of a friction stir processed aluminium alloy was investigated through free inflation tests. Principal parameters of the friction stir process were changed and free inflation tests were performed to assess the formability of the processed sheet. A strong influence of the friction stir process parameters was recorded on the formability of the processed material. Only a specified set of parameters assured a strain behaviour close to the one of the base material.
\end{abstract}

\section{Introduction}

When complex shaped and large parts have to be manufactured, the superplastic forming (SPF) process is one of the best solution for aluminium alloys. The process generally consists in blowing up a heated blank against a die cavity by a gas pressure. Typical temperatures for aluminium alloys range from $450{ }^{\circ} \mathrm{C}$ to $550{ }^{\circ} \mathrm{C}$. At these temperature and at very low strain rates (usually below $5 \times 10^{-2} \mathrm{~s}^{-1}$ ) the material has a very large strain sensitivity index and an extraordinary elongation to failure can be reached without excessive localized thinning [1]. To achieve this kind of behaviour a controlled microstructure is requested for migrograin superplasticity (the most common type of superplasticity). The possibility of reaching elongations much higher than $200 \%$ can bring to significant cost saving benefits: in particular complex shaped components can be manufactured without any joint with a weight reduction and an improvement of its mechanical behaviour [2]. Thermo-mechanical treatments are a consolidated procedure to refine the microstructure and to achieve superplasticity on aluminium alloys. Among other more recent techniques, severe plastic deformation and friction stir process (FSP) techniques have been adopted to obtain ultra-fine grained superplastic materials [3-5]. The FSP has been widely investigated as a refining technique to achieve superplasticity on aluminium commercial alloys but there's still a lack of knowledge about the friction stir as a welding technique to join different aluminium sheets for subsequent SPF operations. Welded blanks are required to reach larger blank size for very large

\footnotetext{
${ }^{a}$ Corresponding author: donato. sorgente@poliba.it
}

This is an Open Access article distributed under the terms of the Creative Commons Attribution License 4.0, which permits unrestricted use, distribution, and reproduction in any medium, provided the original work is properly cited. 


\section{MATEC Web of Conferences}

Table 1. Chemical composition of the superplastic Al-alloy (wt. \%).

\begin{tabular}{|c|c|c|c|c|c|c|c|c|c|}
\hline $\mathbf{S i}$ & $\mathbf{F e}$ & $\mathbf{C u}$ & $\mathbf{M n}$ & $\mathbf{M g}$ & $\mathbf{C r}$ & $\mathbf{Z n}$ & $\mathbf{T i}$ & Others & Al \\
\hline 0.03 & 0.06 & 0.01 & 1.37 & 4.60 & 0.02 & - & 0.01 & $<0.15$ & Balance \\
\hline
\end{tabular}

components and also for multi-sheet applications [6]. Will and Cotton demonstrated that on aluminium alloys the diffusion bonding is not a viable technique since they form a hard and stable $\mathrm{Al}_{2} \mathrm{O}_{3}$ layer on their surface [7]. Further, with conventional fusion welding techniques there's a significant ductility differences between the weld material and parent sheet material at SPF temperatures and strain rates. The weld material has a higher flow stress and lower ductility than the monolithic sheet [8]. Welding techniques with high energy density, e.g. laser beam welding, can lead to more severe temperature cycles than conventional arc welding and then to a finer microstructure in the weld bead. Yan and Zhang reported results on the laser welding of a fine-grained AA5083 aluminium alloy for subsequent SPF of a multi-sheet structure, demonstrating the feasibility of the welding process for the manufacturing of multi-sheet component [9]. On the other hand, a preliminary study on the formability of a laser welded superplastic aluminium alloy were carried out on the ALNOVI-U aluminium superplastic alloy denoting that the grain refining could be not sufficient to achieve a superplastic behaviour in the weld bead [10]. A viable solution is represented by the friction stir welding (FSW): Charit et al. reported an investigation on the FSW of an AA7475 aluminium alloy with the aim of exploring the feasibility of fabrication of multi-sheet structures via FSW/SPF [11]. They highlighted one of the most critical issue in the application of this technology for aluminium alloys: the thermal stability of the fine-grain microstructure in FSWed regions at SPF temperatures. Abnormal grain growth throughout the weld nugget at SPF temperatures results in a reduction of room temperature mechanical properties. This microstructural evolution is strongly related not only to the SPF conditions but also the FSW parameters such as the tool rotational speed and the feed rate [12].

In this work the strain behaviour of a thin FSPed superplastic aluminium alloy sheet was investigated through free inflation tests at a superplastic temperature. The aim is to find suitable process parameters for a FSW operation preceding the SPF process. Principal parameters of the FSP were changed and free inflation tests were performed to assess the formability of the processed sheet in different FSP conditions. The strain behaviour and the formability were assessed by the dome height evolution during the free inflation test and by its value at failure.

\section{Material and methods}

All experiments were performed on a Al-Mg (5XXX series according to Aluminum Association) alloy manufactured by Furukawa-Sky Aluminum Corporation. This alloy is based on the commercial AA5083 alloy but contains a higher Mn weight percentage than the base alloy (see Table 1).

The material is treated by the manufacturer to have a fine grained and stable microstructure and sold under the commercial name of ALNOVI-U. For this work thin sheets (1.35 $\mathrm{mm}$ in thickness) were purchased in the H18 temper and used in FSP tests. Microstructure of the sheet is shown in Fig. 1a. The material has a mean grain size of $8.3 \mu \mathrm{m}$ measured on an metallographic optical microscope by the linear intercept (Heyn) procedure. The superplastic behaviour of this alloy has been formerly investigated and in Fig. 1b the specimen formed in the optimal conditions is reported. The material, in the optimal forming conditions, can reach equivalent strain up to $400 \%$ [13].

\subsection{Friction stir processing}

The tool material was a $56 \mathrm{NiCrMoV7}-\mathrm{KU}$. This is a typical tool steel material, that has high mechanical properties at high temperatures and good toughness at low temperatures. Moreover, in order to improve 


\section{ICNFT 2015}

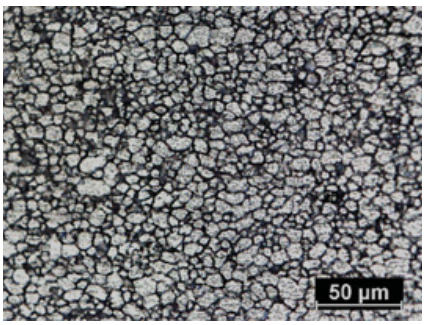

(a)

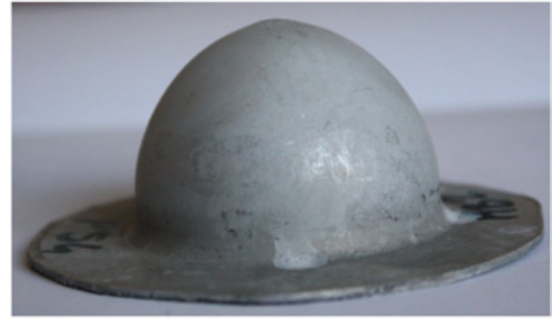

(b)

Figure 1. The microstructure of the fine-grained aluminium alloy ALNOVI-U (a) and the formed specimen at the optimal forming temperature $\left(500^{\circ} \mathrm{C}\right)$ and with the optimal gas pressure (b).

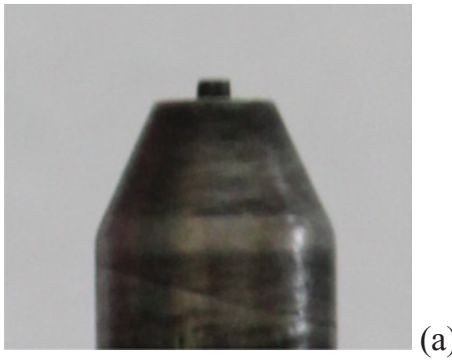

(a)

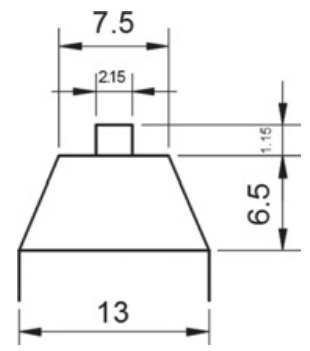

(b)

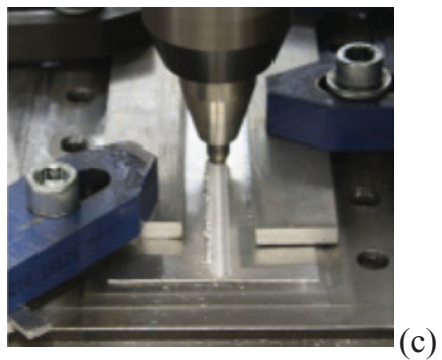

Figure 2. (a) Friction stir welding tool shape and (b) dimensions in mm; (c) Clamping system used during FSP tests.

Table 2. FSP parameters.

\begin{tabular}{|l|c|c|c|}
\hline & Rotational speed [RPM] & Feed rate [mm/min] & Rotational speed/ Feed rate \\
\hline Sample 1 & 500 & 200 & 2.50 \\
\hline Sample 2 & 1000 & 200 & 5.00 \\
\hline Sample 3 & 500 & 400 & 1.25 \\
\hline Sample 4 & 1000 & 400 & 2.50 \\
\hline
\end{tabular}

hardness, and to avoid cracks in the pin which could compromise the FSP process, the tool was processed with a double tempering treatment. The tool geometry was characterized by a $2.15 \mathrm{~mm}$ pin diameter, a $1.15 \mathrm{~mm}$ pin eight and by a shoulder diameter of $7.5 \mathrm{~mm}$, as illustrated in Fig. 2.

The FSP process was carried out using a commercial FSW system, ESAB Legio ${ }^{\mathrm{TM}}$ FSW 4UT. A full factorial plan $2^{2}$ was designed in order to study the effect of two FSP process parameters (rotational speed of the tool and feed rate) on the formability of the processed sheet.

Therefore, ALNOVI-U sheets, $80 \mathrm{~mm}$ wide and $300 \mathrm{~mm}$ long, were FSPed perpendicular to the rolling direction, each one with two different levels of rotational speed and feed rate, according to Table 2. Preliminary tests were performed in order to identify the variability range of rotational speed and feed rate required to avoid structural defects on friction stir processed parts. The tilt angle was kept constant to $1.2^{\circ}$. Three replications for each set of parameters were run.

\subsection{Forming tests}

Specimens were formed by free inflation tests. Tests were carried out on a laboratory scale equipment embedded in the cylindrical split furnace of an INSTRON universal testing machine. The equipment 

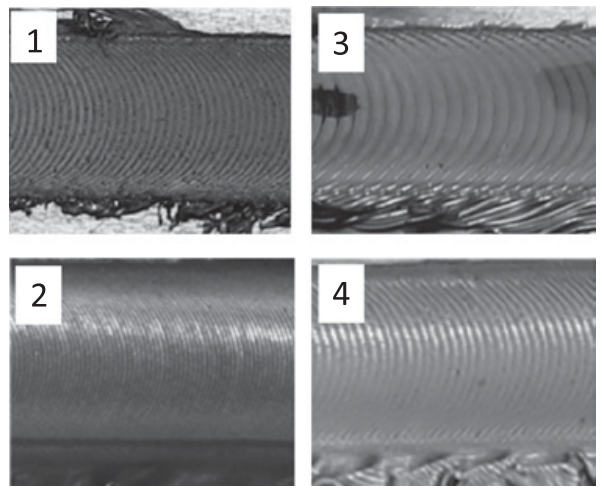

Figure 3. Friction stir processing crowns appearance (corresponding FSP parameters are listed in Table 1).

consists in a female die and in a blank-holder by which the gas is insufflated in the forming chamber. An electronic proportional valve was used to pressurize the forming chamber. The heating of the tools and of the blank was achieved by the electric furnace with its electronic controllers for upper, central and lower zones which can be set with three different temperatures for compensating thermal dispersions. K-type thermocouples were employed to monitor the temperature on the sheet and on the tools. A PC with a data acquisition I/O device by which pressure, temperature, blank-holder force can be monitored and managed. Free inflation tests were performed with a female die having a cylindrical cavity with an entry radius of $3 \mathrm{~mm}$, a $45 \mathrm{~mm}$ diameter and deep enough to achieve the failure of the sheet before it touches the die bottom surface. A position transducer was used to acquire during the whole test the dome height of the specimen. Specimens were cut in circular blanks ensuring that the area of the FSP bead that undergoes superplastic deformation, kept along the diameter, is interested by a stationary condition of the FSP. Constant pressure free inflation tests were then performed in optimal pressure $(0.4 \mathrm{MPa})$ and temperature $\left(500{ }^{\circ} \mathrm{C}\right)$ conditions found in a previous work carried out on the same base material [13]. This in order to compare the superplastic behaviour of the FSPed blank with that of the untreated base material.

\section{Results and discussion}

\subsection{Friction stir processed beads}

The obtained FSPed parts were characterised through a visual inspection of crowns. Figure 3 shows the crowns of the four specimens. Regardless of the range of FSP conditions tested in this work, the obtained FSPed parts did not display any major structural defect. Sample 1 produced a little amount of flash and a smooth surface. Sample 2 produced a very smooth surface and a relevant amount of flash during the process. Sample 3 produced both a rough crown and a certain amount of flash. Sample 4 produced a smooth surface with a relevant amount of flash. The surface appearance of sample 1 and sample 4 is very similar except for the larger amount of flash in sample 4 , which is probably due to the higher rotational speed of the last one. The comparable surface appearance of sample 1 and 4 can be demonstrated by the same tool rotation/feed rate ratio, as shown in Table 2.

These results show a deep influence of process parameters on FSP morphology, being possible to conclude that the best surface finishing was achieved by sample 2 having the highest rotational speed and the lowest feed rate.

For FSP, the two process parameters considered in this work, rotational speed and feed rate are very important. In fact they are responsible of the heat input generated during the process [12]. 


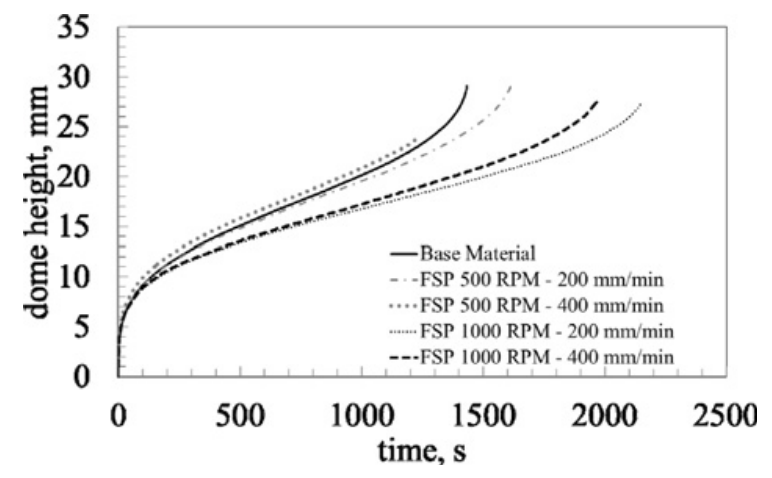

Figure 4. Dome height evolution for different FSP conditions compared with the base material one.

The rotation of the tool results in stirring and mixing of material around the rotating pin and the translation of tool moves the stirred material from the front to the back of the pin and finishes welding process. Higher tool rotation rates generate higher temperatures because of higher friction heating and result in more intense stirring and mixing of material [14].

\subsection{Strain behaviour of FSPed blanks}

In Fig. 4, results of free inflation tests, in terms of dome height versus time curves, are reported together with the curve of the base (unprocessed) material. Both specimens FSPed with the higher rotational speed (1000 RPM), i.e. samples 2 and 4 in Table 2, have a less steep curve than the base material one and they reach a lower dome height at failure. The feed rate, in the highest rotational speed condition, seems to have a not significant effect on the slope of the curve and on the value of the dome height at failure.

Such results are consistent with results achieved in tensile tests at superplastic temperatures conducted by Sanders et al. on a titanium alloy: they reported that welds made with "hotter" FSW parameters (welds made with higher rotational speeds and feed rates) showed less ductility than welds made with comparatively "colder" FSW parameters (slower rotational speeds and feed rates) [6]. They reported also that small changes in the rotational speed have a more significant influence on the thermal energy developed during FSW than a change in the feed rate.

In Fig. 5 the deformed specimens are illustrated for different FSP parameters. As it can be clearly seen, the specimens processed with a lower rotational speed exhibited a more uniform distribution of the strain along the dome.

Asymmetric specimens were obtained when processing the superplastic sheet FSPed with a high rotational speed. The bead of the FSPed zone deformed more slowly than the parent material, the deformation moves to one of the two sides of the dome and the rupture occurs in the base material. When the superplastic sheet is FSPed by lower rotational speed the strain behaviour is close to the one of the base material and symmetric deformed specimens were obtained. Similar results were obtained also at room temperature on an AA5083 aluminium alloy: the formability in FSWed material was improved by decreasing the friction heat flow and was almost the same with that in base material when the material was welded at optimum FSW condition [15]. On the other hand, the specimen FSPed at low rotational speed and high feed rate (sample 3) has a significant lower dome height at failure than the base material. This could be related to the finer grain size that a lower friction heat flow generates: sample 3 is the specimen with the highest ratio between the feed rate and the tool rotation rate (Table 2). The finer grain size promotes the high temperature deformation and the FSP bead undergoes a consistent deformation 


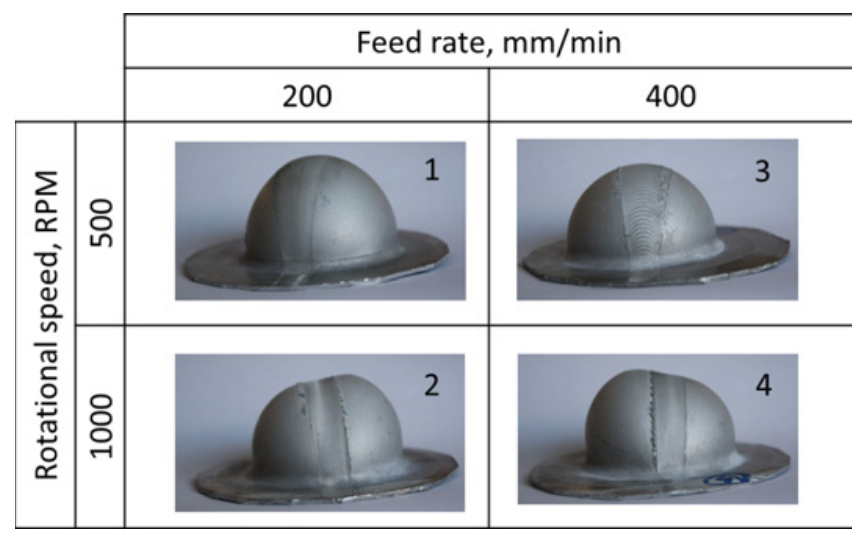

Figure 5. Formed specimens with different FSP conditions.

more than the base material. This result is in accordance with the ones reported on a titanium alloy by Edwards and Ramulu and it demonstrates that an optimal window of FSP parameters exists also for the examined aluminium alloy [12].

\section{Conclusions}

In this work the influence of friction stir processing on the strain behaviour of a superplastic aluminium sheet was investigated. The main conclusions that can be drawn are:

- the strain behaviour at superplastic temperature of a friction stir processed ALNOVI-U alloy is strongly affected by the friction stir process parameters;

- a behaviour close to the base material one can be achieved only for a specified set of friction stir parameters that are, for the investigated thickness $(1.35 \mathrm{~mm})$, a rotational speed of $500 \mathrm{RPM}$ and a feed rate of $200 \mathrm{~mm} / \mathrm{min}$;

- when processing the superplastic sheet with a high rotational tool speed the material deforms more slowly than the base material due to an excess of frictional heat in the stirring and the deformation localizes on the base material.

Even if the aim in multi-sheet application is commonly to have a uniform behaviour and consequently a similar behaviour between the base material and the processed material, it can be also possible to control the friction stir process parameters to achieve a more or less ductile behaviour in different areas of the sheet to get a tailored blank for the superplastic forming operation.

The authors wish to thank the Italian Institutions Region APULIA and MIUR (Ministry of Education, University and Research) for financing the present research activity (TRASFORMA and TISMA projects). The authors also express their gratitude to Ottavio Corizzo for his help in the experiments, to Prof. Luigi Tricarico and Prof. Antonio Domenico Ludovico for their precious support.

\section{References}

[1] G. Giuliano, Superplastic Forming of Advanced Metallic Materials (Woodhead Publishing Limited, Cambridge, 2011)

[2] N. Chandra, Int. J. Non. Linear. Mech. 37, 461 (2002) 


\section{ICNFT 2015}

[3] L.B. Johannes and R.S. Mishra, Mater. Sci. Eng. A, 464, 255 (2007)

[4] Z.Y. Ma, F.C. Liu, and R.S. Mishra, Acta Mater. 58, 4693 (2010)

[5] Z. Ma, R. Mishra, and M. Mahoney, Acta Mater. 50, 4419 (2002)

[6] D. Sanders, P. Edwards, G. Grant, M. Ramulu, and A. Reynolds, J. Mater. Eng. Perform. 19, 515 (2010)

[7] J.D. Will, J.D. Cotton, NASA Technical Report No. NASA/CR-2003-212400, 2003

[8] R.W. Davies, J.S. Vetrano, M.T. Smith, and S.G. Pitman, J. Mater. Process. Technol. 128, 38 (2002)

[9] H.H. Yan and K.F. Zhang, Mater. Des. 31, 2220 (2010)

[10] D. Sorgente, O. Corizzo, M. Brandizzi, and L. Tricarico, J. Mater. Eng. Perform. 23, 4154 (2014)

[11] I. Charit, R.S. Mishra, and M.W. Mahoney, Scr. Mater. 147, 631 (2002)

[12] P. Edwards and M. Ramulu, Sci. Technol. Weld. Join. 14, 669 (2009)

[13] D. Sorgente and L. Tricarico, Int. J. Mater. Form. 7, 179 (2014)

[14] R.S. Mishra and Z.Y. Ma, Mater. Sci. Eng.R. 50, 1 (2005)

[15] T. Hirata, T. Oguri, H. Hagino, T. Tanaka, S.W. Chung, Y. Takigawa, and K. Higashi, Mater. Sci. Eng. A, 456, 344 (2007) 